\title{
The Development of the Human Fetal Adenohypophysis '
}

\author{
JAMES L. CONKLIN \\ Department of Anatomy, The University of Michigan, Ann Arbor, Michigan
}

\begin{abstract}
Understanding the development of the human adenohypophysis is dependent on visualizing the growth of Rathke's pouch. This embryonic structure gives rise to bilateral anterior and posterior, superior and inferior segments. These segments differ in their potential to produce various types of hypophyseal chromophils. The potential differences are described in the text.

Further, by application of specific staining procedures it has been possible to determine the approximate time that specific chromophils appear in the adenohypophysis. The chromophils of the adenohypophysis develop in the order: cell type III, I, IV, II, V, VI and IX. There may be a relationship between the development of certain chromophils and the onset of function in target endocrine glands.
\end{abstract}

Present descriptions of the cytogenesis of hypophyseal chromophils are incomplete (Romeis, '40; Pearse, '52; Falin, '61). Two apparent reasons are the lack of a range of suitable material for study and the use of staining procedures that were not specific for individual cell types.

In previous studies I have attempted to evaluate the specificity of the available staining methods and to provide a description of the chromophils of the adult adenohypophysis (Conklin, '66, '68). In all, seven specific chromophils as well as variant forms were identified.

The specific chromophils and the hormone tentatively secreted by each are as follows: cell type I: somatotropic hormone (STH); type II: lactotropic hormone (LTH); type III: adrenocorticotropic hormone (ACTH); type IV: thyrotropic hormone (TSH); type V: luteinizing hormone (LH); type VI: follicle stimulating hormone (FSH) (see Ezrin, '63; van Ordt, '65; Conklin, '66 for terminology). The significance of three other cell types, i.e., VII, VIII and IX is not clear. Cell types VII and VIII appear to be variant forms of the definitive chromophils while type IX is a definitive cell of unknown function.

In the present study, the methods employed to demonstrate each of the above chromophils have been applied to the fetal hypophysis in order to determine the time of appearance and origin of each cell type.

\section{MATERIALS AND METHODS}

The material employed in this study consisted either of whole embryos, heads of fetuses or fetal pituitary glands obtained from the Embryology Research Collection of the Department of Anatomy, The University of Michigan. Thirty-eight specimens ranging in crown-rump (CR) length from $11.5 \mathrm{~mm}$ to $365 \mathrm{~mm}$ (term) were used. The specimens were fixed in either $10 \%$ neutral formalin or Bouin's solution. Tissue sections were stained by several different staining procedures and identification of specific chromophils was achieved by the use of methods described in previous publications (Conklin, '66, '68).

Particular attention was given to (1) the histogenesis of various regions of the hypophysis and (2) the time, based on crownrump measurements, of appearance of tinctorially distinct chromophils. The staining reaction of intracellular cytoplasmic inclusions was the basis for identifying a specific chromophil. The appearance of stained inclusions was not inferred to be precisely coincident with the onset of function, but the appearance of specifically stained inclusions was interpreted as morphological evidence of functional capability.

To understand the development of the adenohypophysis it was necessary to recon-

1 Research supported by grant HD 00557 from the National Institute of Child Health and Human Development, National Institutes of Health. 
struct Rathke's pouch. In making this reconstruction the conventional wax plate method was employed.

\section{OBSERVATIONS}

After its invagination from the surface ectoderm, Rathke's pouch (11.5 mm CR) had a trilobed appearance not unlike the shape of a W (figs. 9, 10). The open face of the pouch projected in an anterior direction and the lateral limbs extended slightly forward of the center. Mesenchyme in the immediate vicinity was loosely arranged and contained many, small blood capillaries. From this stage until that represented by sections from a $60 \mathrm{~mm}$ CR fetus (fig. 7) two concurrent processes occurred.
These were (1) changes in the size and configuration of Rathke's pouch and (2) epithelial proliferation.

To fully understand the development of Rathke's pouch it was necessary to reconstruct its configuration at various stages. At the time of greatest development (fig. 1) Rathke's pouch was subdivided into several parts. There was a transverse segment which lay immediately in front of the developing pars nervosa (fig. 7). This portion was derived from the lumen of the original invagination. All other parts were outgrowths from the anterior face of this original segment. From the anterior face of the transverse lumen bilateral superior and inferior limbs (figs. 3-5) were pro-

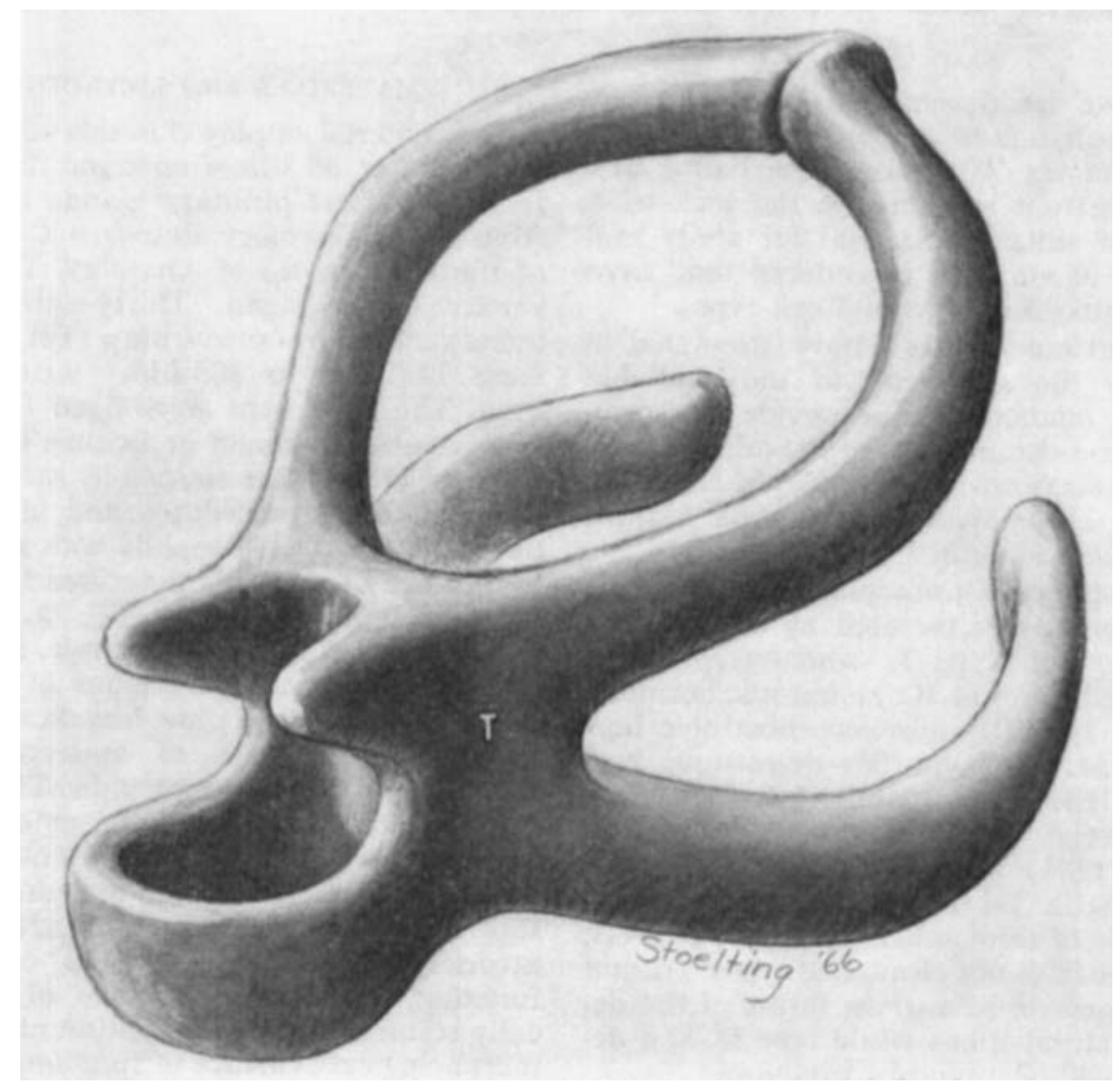

Fig. 1 Schematic diagram of a reconstruction of Rathke's pouch at its greatest develop. ment. Anterior (right), superior (top). Note that there is a transverse segment ( $T$ ) that is continuous with left and right, anterior and posterior, inferior and superior limbs. The posterior limbs partially enclose the neurohypophysis while the anterior limbs surround mesenchyme ventral to the hypothalamus. 
jected. The right and left superior limbs were confluent in the midline (fig. 12) while the right and left inferior limbs were not. The superior and inferior limbs of each side originated from the two lateral projections seen at the $11.5 \mathrm{~mm} \mathrm{CR}$ stage. The anterior limbs enclosed the mesenchyme ventral to the hypothalamus. The posterior limbs projected from the upper and lower anterior face of the transverse segment of Rathke's pouch. Both left and right, posterior superior limbs were superior to the developing pars nervosa and partially surrounded the infundibulum. The posterior inferior limbs were variable in configuration. They were sometimes observed as separate projections, inferior and lateral to the pars nervosa, or more frequently they were joined to form a cup-like confluens around the ventral surface of the pars nervosa.

The development of the various limb segments of Rathke's pouch was progressive. Small anterior limbs were evident at about the $11 \mathrm{~mm}$ CR stage (figs. 9, 10) and the entire system reached maximum development by $60 \mathrm{~mm} \mathrm{CR}$.

The occurrence of the limbs of Rathke's pouch was transitory. In the adult gland only the transverse segment was prominent and persisted in part, as the so-called residual cleft (fig. 8). The limbs of the pouch usually disappeared as the result of epithelial proliferation that obliterated the lumen except for colloid-containing, follicular remnants found in the adult gland. These follicles were most numerous in the superior and inferior regions of the anterior zone of the pars distalis, and in the pars tuberalis.

In the youngest specimen, Rathke's pouch was lined by a layer of small, stratified cuboidal, epithelial cells. These cells exhibited many mitotic figures indicating their participation in the development of the limbs of Rathke's pouch. Initial epithelial growth occurred at the distal ends of the lateral projections. Penetration of the mesenchyme by epithelial cell cords and subsequent rearrangement to form a lumen extended the limbs of the pouch. The anterior superior segments grew lateral, forward and medial to meet in the midline and isolated a central mass of mesenchyme (fig. 11). This central mesenchyme was also partially enveloped by the inferior limbs. From the distal, medial union the cell cords turned posterior and subsequently met with cell cords from the anterior medial face of the transverse cleft. The result of this growth was to divide the mesenchyme into two halves that were partially enclosed by an epithelial shell derived from the superior and inferior limbs (fig. 12).

Simultaneously, cellular proliferation at the medial surface of the epithelial-mesenchymal junction produced multiple cell cords that grew into the mesenchyme (figs. 13, 14). This epithelial proliferation was initially most extensive from the anterior face of the cleft but eventually spread distally so that each of the mesenchymal islands was invaded by epithelial cords from the adjacent limbs of Rathke's pouch. Cellular proliferation from the anterior limbs proceeded toward the medial mesenchyme while proliferation from the posterior inferior limbs was in a lateral direction and proliferation of the posterior superior limbs occurred in situ (summarized in fig. 2). Epithelial proliferation from various parts of the limbs of the pouch occurred in the order: (1) anterior face of transverse cleft; (2) anterior inferior limbs; (3) anterior superior limbs; (4) posterior inferior limbs; (5) posterior face of the cleft; (6) posterior superior limbs. The interval between the onset of proliferation from 1-4 (above) was several days and no attempt was made to obtain precise timing. Evidence of cellular proliferation, most apparent in these areas through the $60 \mathrm{~mm} \mathrm{CR}$ stage, was observed throughout the fetal period.

Cellular proliferation from the posterior face of the transverse cleft was first observed in a $63 \mathrm{~mm} \mathrm{CR}$ fetus (fig. 18). The cells from the posterior face invaded the thin layer of mesenchyme between Rathke's pouch and the pars nervosa. Extensive proliferation of the epithelia of the posterior superior limb was first observed in a $160 \mathrm{~mm}$ CR fetus.

As the cell cords invaded the mesenchyme of the anterior zone they formed an extensive anastomosing network. The intervening mesenchyme was richly supplied with blood capillaries and the cell cords were in close proximity to the capillaries 

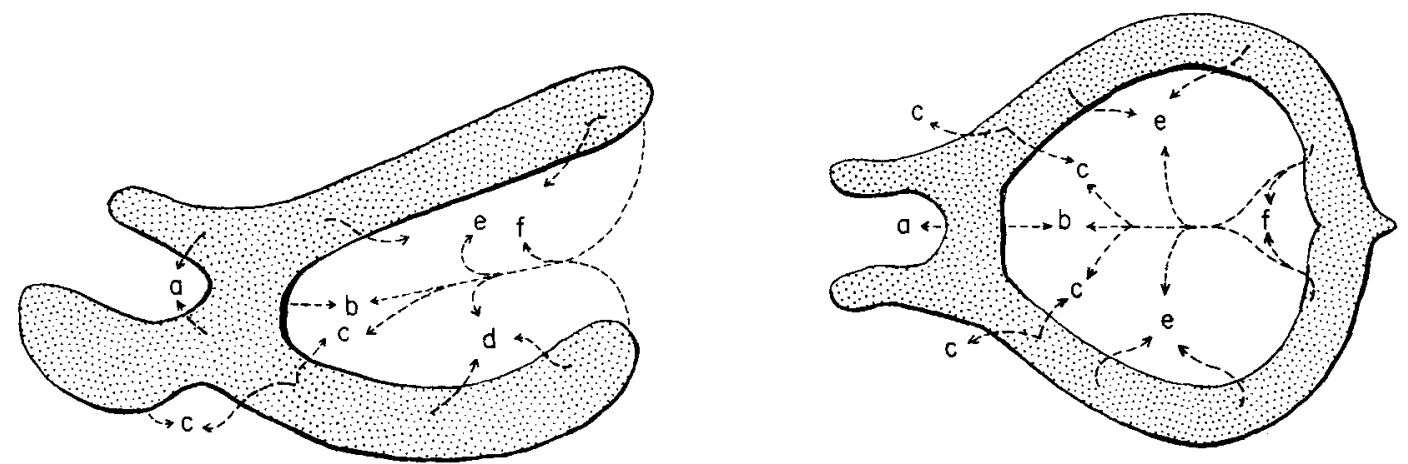

Fig. 2 Schematic views of the adenohypophysis from above (right) and lateral (left). The arrows indicate the direction of epithelial proliferation and the regions of the gland where certain cell types originate and predominate. These are (a) types III-VII, IX (posterior zone only), (b) type III, (c) type I and II, (d) type IV, (e) type VI, (f) type V.

(fig. 15). By $120 \mathrm{~mm} \mathrm{CR}$ most of the initial mesenchymal islands were penetrated by epithelium although some connective tissue septa persisted. The latter are seen in the adult gland along the course of the major vessels.

Cytogenesis of specific chromophils was progressive. Initially, certain chromophils appeared in the region of the epithelial-mesenchymal junction and later other chromophils appeared in the cell cords in other regions of the gland. Scattered cells in given areas exhibited a more pronounced basophilic cytoplasm. The cells gradually increased in size and small tinctorially distinct inclusions were observed in the cytoplasm. The type III cell was the first definitive chromophil observed in the fetal hypophysis. It was seen in the gland of a $20 \mathrm{~mm} \mathrm{CR}$ fetus and identified by its characteristic staining with PAS and orange G. These initial type III cells were located at the junction of mesenchyme and epithelial cells derived from the anterior face of the transverse lumen (fig. 14) of Rathke's pouch.

Carminophilic type I cells and alcian blue-PAS positive type IV cells were first observed in glands from $65 \mathrm{~mm}$ and 78 mm CR fetuses, respectively. Like the type III cells they initially were found in the region of the epithelial-mesenchymal junction. Type I cells were derived principally from the epithelium of the posterior inferior limb. Type IV cells initially appeared in the region of the anterior inferior limb (fig. 16).
Development of these three cell types occurred in two distinct patterns. The first was the initial appearance of cells from a particular epithelial source at the site of the epithelial-mesenchymal junction. The second was the gradual increase in number of specific cells following the loss of the mesenchymal islands (fig. 17). The epithelial source of the latter cells could not be determined because of the anastomosing arrangement of the cell cords. However, the respective cells accumulated in the same general region where they were first observed.

Other specific chromophils developed in the anterior zone of the pars distalis after invasion of the mesenchymal islands by the cell cords. Erythrosinophilic type II cells developed in the same region as the type I cells and were first observed in the $170 \mathrm{~mm}$ CR fetus. Alcianophilic type V cells were seen initially in the anterior medial region of the pars distalis of a $205 \mathrm{~mm}$ CR fetus. The indifferent cells in this area originated from the distal ends of both the superior and inferior limbs. Type VI cells were produced from indifferent cells from the anterior superior limb. Type VI cells, stained by alcian blue, PAS and orange G, were first seen in sections from a $270 \mathrm{~mm}$ CR fetus.

The time at which the indifferent epithelia of the posterior superior limb developed into definitive chromophils of the pars tuberalis was not determined. Epithelial proliferation in this region was first observed at $160 \mathrm{~mm} \mathrm{CR}$. The pars tuberalis of a term fetus contained definitive chro- 
mophils indicating that development of these cells, tinctorially like the type $\mathrm{V}$ chromophils, occurred sometime during the last half of the fetal period.

Epithelia from the posterior face of the transverse lumen invaded the mesenchyme adjacent to the pars nervosa and formed irregular cell clusters and follicles (fig. 19). Development of chromophils in this region occurred much later than in the anterior zone. Cell types III-VI were first observed in the posterior zone of a $290 \mathrm{~mm}$ $\mathrm{CR}$ fetus. However, these cells were not present in the posterior zone of all fetal glands. Cell type IX was consistently present in the posterior zone of all fetal glands after $310 \mathrm{~mm}$ CR (Conklin, '66).

The fetal ages, based on crown-rump measurements (Patten, '53), that specific chromophils were first observed was as follows:

\begin{tabular}{cccc}
\hline CR length & Fetal age & Cell type & $\begin{array}{c}\text { Hormone } \\
\text { secreted }\end{array}$ \\
\hline$m m$ & weeks & & \\
20 & 7 & III & ACTH \\
65 & 11 & I & STH \\
78 & 12 & IV & TSH \\
170 & 19 & II & LTH \\
205 & 22 & V & LH \\
270 & 28 & VI & FSH \\
310 & 32 & IX & $?$ \\
\hline
\end{tabular}

${ }^{1}$ Conklin, '66, '68.

\section{DISCUSSION}

The reconstructions of the limbs of Rathke's pouch were most useful in determining the origin of various regions of the adenohypophysis. The origin of the pars tuberalis and its relationship to the infundibulum was evident when it was found that this part of the adenohypophysis was derived from the posterior superior limbs of Rathke's pouch (fig. 1). The contribution of the remaining parts of the limbs to the pars distalis clearly explained the origin of the latter.

Of considerable interest was the differing cytological potential of various segments of the limbs of Rathke's pouch. True acidophils (cell type I and II) were derived only from anterior face epithelium while mucoid cells developed from both anterior and posterior face epithelium. The site of initial development of certain chromophils (types I, III and IV) would suggest an epithelial-mesenchymal interaction such as demonstrated in other glands (Grobstein, '62).

While Hammar ('25) observed acidophils in the gland of a $22 \mathrm{~mm}$ CR embryo, Romeis ('40) described the initial appearance of basophils in a $30 \mathrm{~mm}$ CR fetus and acidophils in a $140 \mathrm{~mm} \mathrm{CR}$ fetus. Falin ('61) also confirmed that basophils developed before acidophils but disagreed with Romeis as to when the cells appeared. These investigators were not able to identify specific chromophils because of the nonspecificity of the methods they employed.

The appearance of certain of the chromophils can be correlated with the onset of function in certain target endocrine organs. Gillman ('48) reported that the adrenal cortex exhibited morphological evidence of hormone production in the ninth week. This is two weeks after the appearance of the type III cells. The thyroid gland accumulated $I_{131}$ in the sixteenth week (Mitskevich, '59) although colloid was present by the eighth week (Gillman, '48). Type IV cells were present in the twelfth week. The appearance of type I cells in the eleventh week is coincident with the completion of the initial stages of organogenesis and the initiation of the rapid growth phase of fetal development (Patten, '53).

Gonadotropic cells were observed in the fetal hypophysis by Midgley ('66) although they were not demonstrated by the tinctorial method of Swanson and Ezrin ('60). In the present study they appeared near the end of the second trimester and persisted through the remainder of the fetal period. As noted previously (Conklin, '66) type II cells were larger and more numerous in the fetal gland than in the adult, perhaps because of a relationship to fetal lactation.

The appearance of secretory material in the cytoplasm of chromophils does not imply that the cells were secreting. However, it does reveal that all chromophils probably had the ability to synthesize and may have had the capability of secretion during the fetal period. The correlation between the appearance of certain chromophils and the onset of function in certain target endocrine glands may be more than 
coincidental. Limited as they are, these direct observations of the development of chromophils in the human fetal hypophysis may be useful for interpreting the role of the endocrine system in human fetal development.

\section{ACKNOWLEDGMENTS}

The author is indebted to Mrs. Lana Brock and Mrs. Dorothy Kangas for assistance in preparation of the material and manuscript.

\section{LITERATURE CITED}

Conklin, J. L. 1962 Cytogenesis of the human fetal pancreas. Am. J. Anat., 111: 181-193. 1966 The identification of acidophilic cells in the human pars distalis. Anat. Rec., 156: 347-360.

1968 A histochemical study of mucoid cells in the pars distalis of the human hypophysis. Anat. Rec., 160: 59-78.

Ezrin, C. 1963 In: Discussion Generale, Cytologie de l'adenohypophyse. Ed. by J. Benoit and C. Da Lage. Paris. Editions of C.N.R.S., p. 346.

Falin, L. I. 1961 The development of human hypophysis and differentiation of cells of its anterior lobe during embryonic life. Acta Anat., 44: 188-205.

Gillman, J. 1948 The development of the gonads in man, with consideration of the role of fetal endocrines and histogenesis of ovarian tumors. Contrib. Embryol., 32: 81-132.
Grobstein, C. 1962 Interactive processes in cytodifferentiation. J. Cell. and Comp. Physiol., Suppl. 1, 60: 35-48.

Hammar, J. A. 1925 A quelle epoque de la vie foetale de l'homme apparaissent les primiers signes d'une activite endocrine. Upsala Lakareforenings forhandlingar. Ny Foljd., 30: 375392.

Midgley, A. R. 1966 Human pituitaxy luteinizing hormone: An immuno-histochemical study. J. Histochem., 14: 159-166.

Mitskevich, M. S. 1957 Glands of Internal Secretion in the Embryonic Development of Birds and Mammals. Publ. by The Academy of Sciences of USSR, Moscow.

Patten, B. M. 1953 Human Embryology, 2nd Edition. The Blakiston Company, New York.

Pearse, A. G. E. 1952 Observations on the localization, nature and chemical constitution of some components of the anterior hypophysis. J. Path. Bact., 64: 791-810.

Romeis, B. 1940 Inner sekretorische Drusen. II. Hypophyse. In: Handbuch der Microskopischen Anatomie des Menschen. Ed, by W, von Mollendorf, publ. by Julius Springer, Berlin.

Swanson, H. E., and C. Ezrin 1960 The natural history of the delta cell of the human adenohypophysis: in childhood, adulthood and pregnancy. J. Clin. Endocr., 20: 952-966.

van Oordt, P. G. W. J. 1965 Nomenclature of the hormone producing cells in the adenohypophysis. A report of the International Committee for Nomenclature of the Adenohypophysis. Gen. Comp. Endocr., 5: 131-134. 
PLATES 
PLATE 1

EXPLANATION OF FIGURES

All figures are sagittal or parasagittal sections of the hypophysis. The arrow in the upper left corner points in the anterior direction.

3 A portion of the neurohypophysis is indicated by the solid arrow. The open arrow points to the adenohypophysis. The $x$-shaped configuration of the lumen of Rathke's pouch is apparent in this lateral view. Anterior superior, inferior and posterior superior, inferior limbs of the pouch are visible. $20 \mathrm{~mm} \mathrm{CR}$. Hematoxylin and eosin. $\times 40$.

4 The solid arrow indicates the neurohypophysis. The open arrow indicates Rathke's pouch and portions of some of its branches. $25 \mathrm{~mm}$ CR. Masson trichrome. $\times 40$.

5 This parasagittal section reveals the superior suspension (arrow) of the vascular mesenchyme found in the interior of the developing adenohypophysis. $25 \mathrm{~mm}$ CR. Masson trichrome. $\times 40$.

6 A segment of the residual Iumen (L) of Rathke's pouch. Even at this later stage of development there is a marked difference in the integrity of the basement membrane adjacent to the anterior (right) and posterior (left) faces of the pouch. This difference probably is the result of greater cellular proliferation from the anterior lining epithelium. PAS and performic acid-alcian blue. $115 \mathrm{~mm} \mathrm{CR}$. $\times 160$.

7 This section illustrates the relationship between the developing adeno- and neurohypophysis. The infundibular stalk (I) and pars nervosa (N) are visible. Of the adenohypophysis, only the anterior zone of the pars distalis (D) is evident. The arrows indicate four segments of the luminal branches of Rathke's pouch. Note particularly their relationship to the neurohypophysis. $60 \mathrm{~mm} \mathrm{CR}$. Hematoxylin and eosin. $\times 40$.

8 In this hypophysis from a term fetus, all portions of the gland are evident. Infundibulum (I), pars nervosa (N), posterior zone of the pars distalis ( $\mathrm{pD}$ ), colloid-filled remnants of the residual cleft $(\mathbf{R})$, anterior zone of the pars distalis (aD) and pars tuberalis (T). Compare the topography of this gland with figure 7 . Aldehyde fuchsin and Masson trichrome. $\times 16$. 


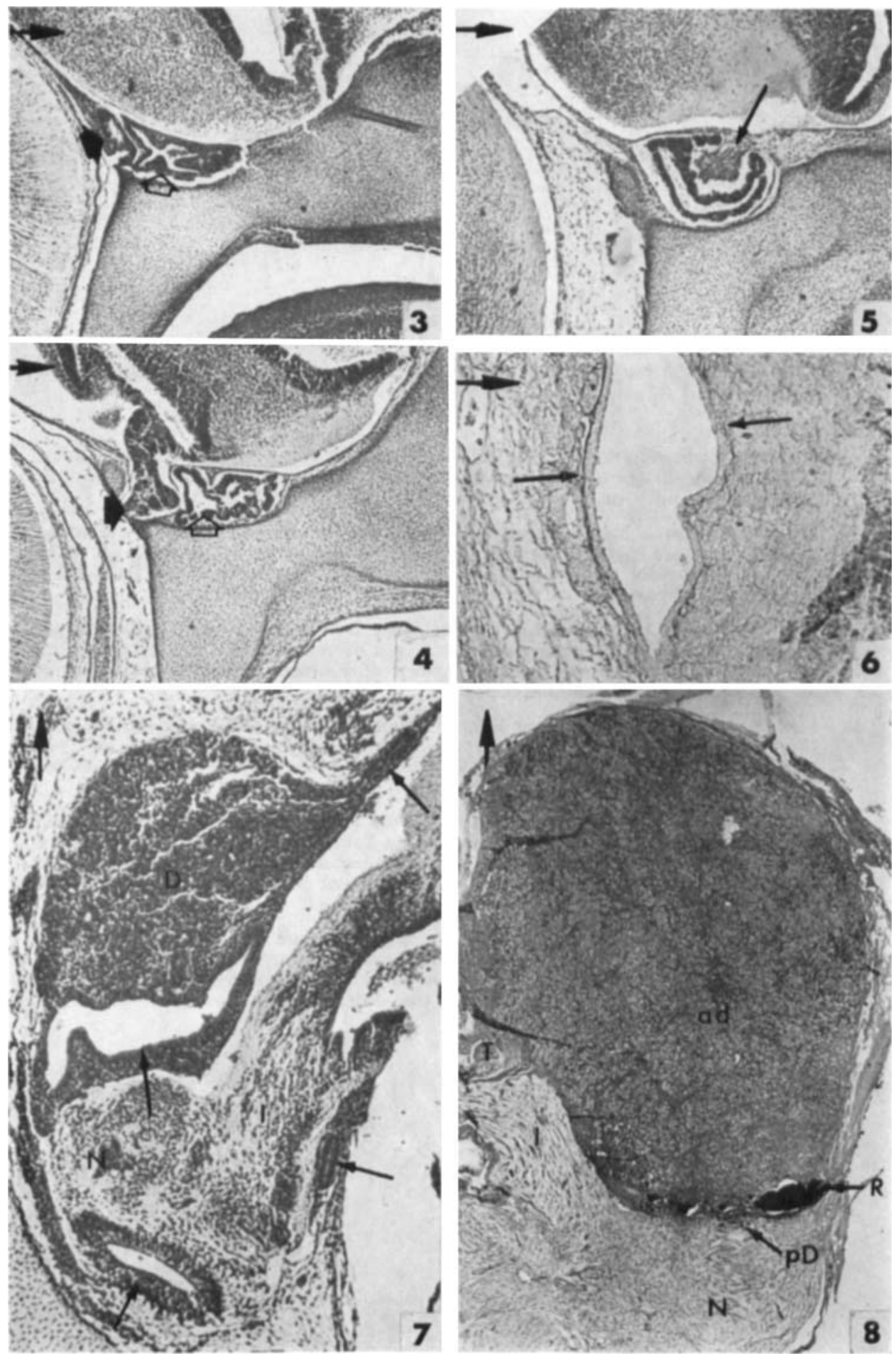


PLATE 2

EXPLANATION OF FIGURES

All sections are in the transverse plane. The arrow in the upper left points in an anterior direction.

9 Note the W-shaped configuration of Rathke's pouch (open arrow). Future cellular proliferation will occur most extensively from the lateral limbs. $11.5 \mathrm{~mm} \mathrm{CR}$. Hematoxylin and eosin. $\times 40$.

10 As Rathke's pouch increases in size, it gives rise to anterior and posterior limbs which proliferate in the direction indicated (small arrows). The posterior limbs envelope the neurohypophysis (large arrow) while the anterior limbs surround a portion of mesenchyme. $19 \mathrm{~mm} \mathrm{CR}$. Masson trichrome. $\times 40$.

11 As the anterior limbs of Rathke's pouch grow forward, they eventually turn toward the midline (arrows) isolating an island of central mesenchyme. Epithelial proliferation from the entire anterior face of Rathke's pouch is also evident. $36 \mathrm{~mm}$ CR. Masson trichrome. $\times 40$.

12 Fusion of the anterior limbs of Rathke's pouch in the midline and cellular proliferation in the direction indicated (open arrow) divides the mesenchyme (m) into two portions, each surrounded by epithelial cells. $45 \mathrm{~mm}$ CR. Masson trichrome. $\times 40$.

13 Further development of the gland involves the proliferation of both mesenchyme and epithelia as indicated by the increase in both components. The epithelia, in the form of branching cords of cells, gradually invades the principal mesenchymal islands $(\mathrm{m})$. The infundibulum (I) is also present in this section. $91 \mathrm{~mm} \mathrm{CR}$. Masson trichrome. $\times 40$.

14 Initial differentiation of identifiable chromophils occurs at the periphery of the mesenchymal islands. The arrows indicate the position of chromophils in this specimen (fig. 12). These type III chromophils are developing from the anterior medial face of Rathke's pouch. $45 \mathrm{~mm}$ CR. Masson trichrome. $\times 40$. 

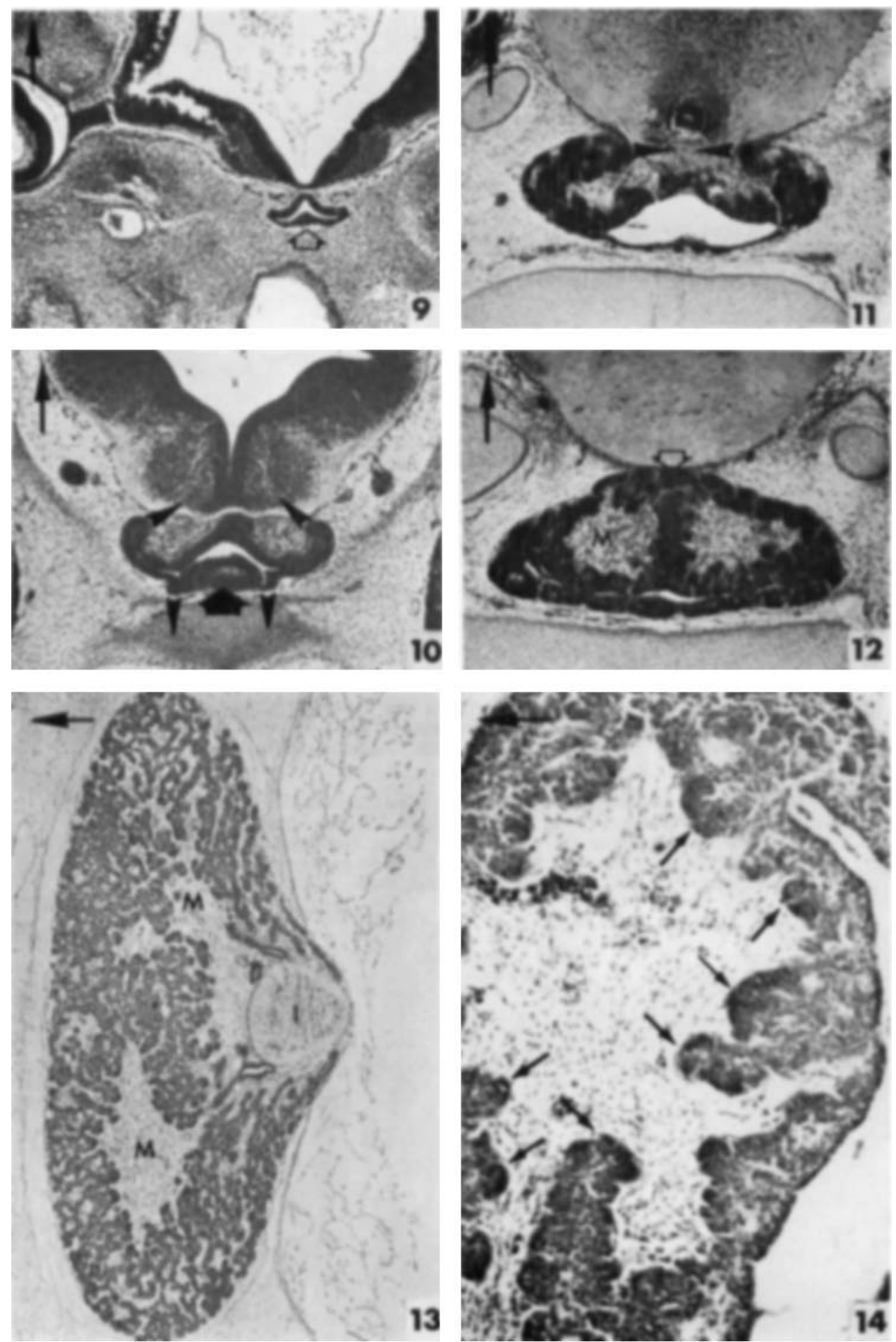
PLATE 3

EXPLANATION OF FIGURES

15 A higher powered view of the epithelial cell cords and intervening mesenchyme. Many blood capillaries (arrows) are evident in the mesenchyme. $154 \mathrm{~mm}$ CR. Masson trichrome. $\times 640$.

16 By the fifteenth week of development only remnants of the mesenchymal islands remain. However, the type IV chromophils (arrows) still occur only at the epithleial-mesenchymal junction. $120 \mathrm{~mm}$ CR. Aldehyde fuchsin and Masson trichrome. $\times 160$.

17 A view of the anterior zone of the pars distalis from a term fetus. This section illustrates the frequency of mucoid cells (dark) at this stage of development. The intervening areas are composed of indifferent cells (chromophobes) and acidophils. $365 \mathrm{~mm} \mathrm{CR}$. PAS and performic acid-alcian blue.

18 This parasagittal section illustrates the onset of epithelial proliferation (arrows) from the posterior zone of the pars distalis. The lumen of Rathke's pouch (L). $63 \mathrm{~mm}$ CR. Aldehyde fuchsin and Masson trichrome. $\times 40$.

19 The cells of the posterior zone are found in the posterior wall of the residual lumen (L), in cell clusters or follicles (arrows). They occur principally within the connective tissue between the residual cleft and the pars nervosa (N). Only mucoid cells are observed in this region. $310 \mathrm{~mm} \mathrm{CR}$. Herlant tetrachrome. $\times 400$. 

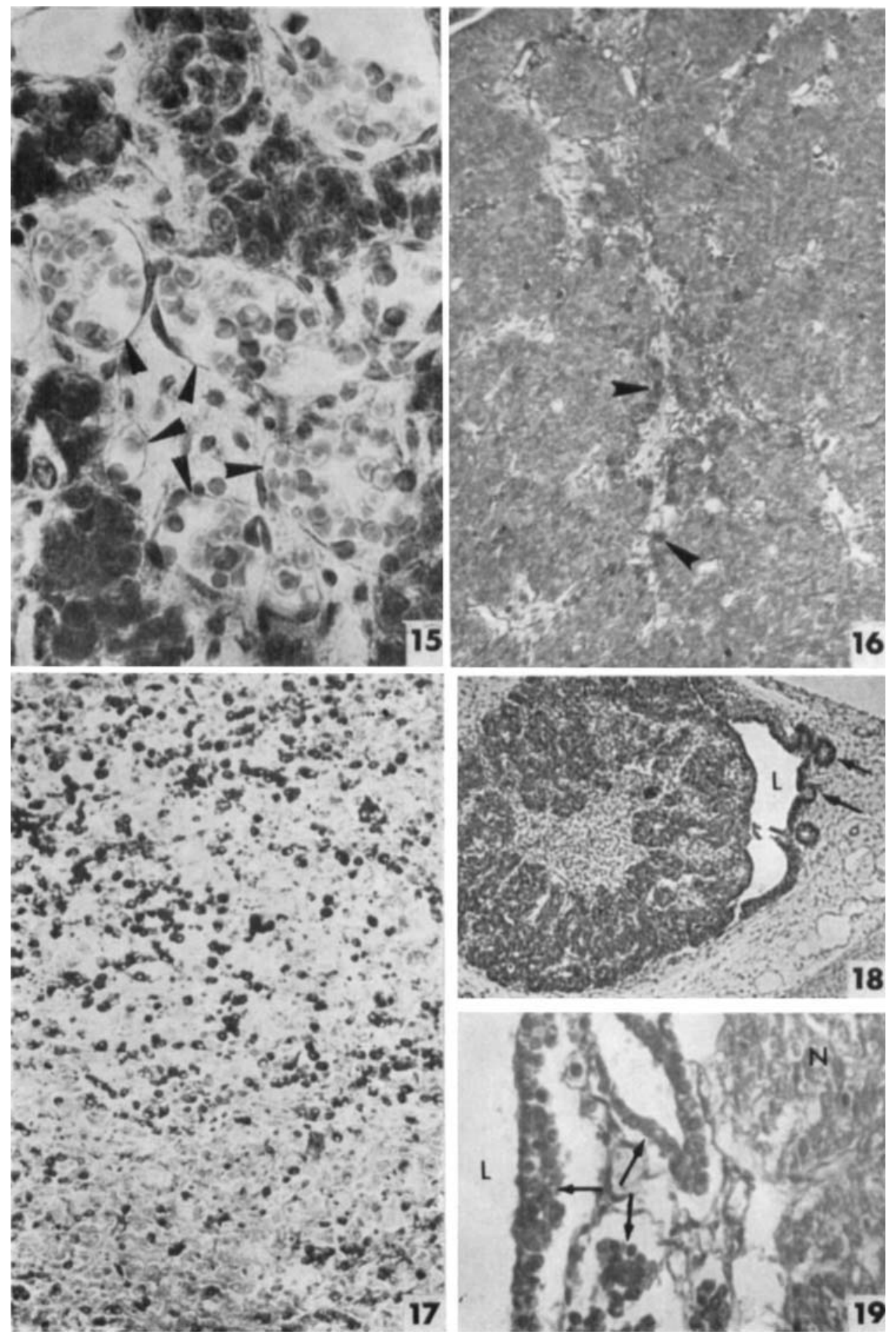